\title{
Nanostructured Titanium Nitride as a Novel Cathode for High Performance Lithium/Dissolved Polysulfide Batteries
}

\author{
Negar Mosavati ${ }^{a}$, Venkateswara Rao Chitturi ${ }^{a}$, Steven O. Salley ${ }^{a}$, K. Y. Simon Ng a, \\ ${ }^{a}$ Department of Chemical Engineering and Materials Science, Wayne State University, \\ Detroit, MI 48202, USA
}

*Corresponding author: K. Y. Simon Ng;

E-mail address: sng@wayne.edu; Fax: +1 313577 8171; Tell: +1 3135773805 


\begin{abstract}
Lithium-sulfur (Li-S) batteries could potentially revolutionize the rechargeable battery market due to their high energy density and low cost. However, low active material utilization, electrode volumetric expansion and a high rate of capacity fade due to the dissolution of lithium polysulfide intermediates in the liquid electrolyte are the main challenges facing further Li-S battery development. Here, we enhanced Li-S batteries active material utilization and decreased the volumetric expansion by using the lithium/dissolved polysulfide configuration. Moreover, a novel class of cathode materials, Titanium Nitride (TiN), was developed for polysulfide conversion reactions. The surface chemical environment of the TiN has been investigated by X-ray photoelectron spectroscopy (XPS) analysis. The existence of S-Ti-N bonding at the cathode electrode surface was observed, which indicates the strong interactions between TiN and polysulfides. Therefore, the TiN electrode retains the sulfur species on the cathode surface, minimizing the active material and surface area loss and consequently, improves the capacity retention. The resultant cells demonstrated a high initial capacity of $1,524 \mathrm{mAh} \mathrm{g}^{-1}$ and a good capacity retention for 100 cycles at a C/10 current rate.
\end{abstract}

\title{
Keywords
}

Lithium sulfur battery; Dissolved Polysulfide; Cathode material; Titanium Nitride 


\section{Introduction}

Advances in portable electronic devices and electric vehicles require efficient electrical energy storage systems, such as rechargeable batteries with high energy density and long lasting cycle performance. Among the most promising energy storage systems, lithium-sulfur (Li-S) batteries could significantly improve the rechargeable battery market due to their high energy density of 2,600 Wh kg ${ }^{-1}$ and theoretical capacity of 1,675 mAh $\mathrm{g}^{-1}$ [1]. In addition, sulfur is environmentally friendly and has a low cost [1-3]. However, there are some challenges facing Li-S battery development, such as: low active material utilization, high selfdischarge products, volumetric expansion associated with intermediate products, and high rate of capacity fade due to the dissolution of lithium polysulfide intermediates in liquid electrolyte, which also increase the redox shuttle reactions and lithium corrosion $[1,3,4]$. In order to overcome these obstacles, many studies have attempted to develop various cathode materials such as functionalized carbon materials, graphene oxides, and conducting polymers with high surface area and porosity [4-9]. These materials were designed to enhance Li-S cell capacity retention due to their ability to maintain polysulfides by physisorption, or to chemisorb lithium polysulfides because of their hydrophilic nature [10, 11]. Metal oxides, such as $\mathrm{TiO}_{2}, \mathrm{Al}_{2} \mathrm{O}_{3}$ and $\mathrm{SiO}_{2}$ as well as metal sulfides, such as $\mathrm{TiS}_{2}$ and $\mathrm{ZrS}_{2}$ were also reported to adsorb lithium polysulfides and reduce redox shuttle reactions in Li-S batteries [12-16]. In addition, $\mathrm{Ti}_{4} \mathrm{O}_{7}$ has been demonstrated to enhance the redox chemistry and cyclability due to its sulfiphilic surface and good electron conductivity [17].

On the other hand, a dissolved polysulfides configuration has been reported to have high reaction activity and sulfur utilization compared to conventional Li-S batteries [18-20]. Barchasz et al. demonstrated that the discharge capacity could be increased to up to 1,400 
mAh $\mathrm{g}^{-1}$ at a low rate of $\mathrm{C} / 100$, using carbon foam and dissolved $0.5 \mathrm{~mol} \mathrm{~L}^{-1} \mathrm{Li}_{2} \mathrm{~S}_{6}-\mathrm{Li}_{2} \mathrm{~S}_{8}$ catholyte. However, its capacity decreases to $1,200 \mathrm{mAh} \mathrm{g}^{-1}$ within 10 cycles [21]. Demir-Cakan et al. showed the capacity performance of $\mathrm{Li}_{2} \mathrm{~S}_{5}$ with a Ketjen Black carbon cathode at $\mathrm{C} / 10$ rate. Their results show an almost 1,200 to $500 \mathrm{mAh} \mathrm{g}^{-1}$ capacity, and 500 to $300 \mathrm{mAh} \mathrm{g}^{-1}$ capacity deactivation for 0.3 and $0.1 \mathrm{M} \mathrm{Li}_{2} \mathrm{~S}_{5}$ catholyte concentrations, respectively, within 70 cycles [22]. The low performance of carbon materials is mainly due to their poor adsorption properties toward lithium polysulfides. Therefore, in order to take full advantage of dissolved polysulfide Li-S battery, it is important to enhance its capacity retention and cycle lifetime using efficient cathode materials. The studies that emerged from the reported works indicate that the battery performances centred mainly on the development of cathode materials.

Based on our experiences in improving the battery performances using nanostructured electrodes [20, 23, 24], we investigated transition metal nitrides as a new class of cathode materials and demonstrated the superior performance in a Li/dissolved polysulfide battery configuration for the first time. Transition metal nitrides are well known materials for supercapacitors and lithium-ion batteries due to their high reversible insertion and extraction of ionic species and the capability of storing lithium by the intercalation mechanism [25-30]. Different types of metal nitride such as TiN [31], $\mathrm{VN}$ [32], $\mathrm{Mo}_{2} \mathrm{~N}$ [33, 34], $\mathrm{Zn}_{3} \mathrm{~N}_{2}$ [35], $\mathrm{Ni}_{3} \mathrm{~N}$ [36], $\mathrm{NbN}$ [37], have been demonstrated as efficient electrode materials for lithium-ion batteries and supercapacitors. Among the metal materials, titanium nitride (TiN) has unique properties such as high electrical conductivity $\left(4,000-55,500 \mathrm{~S} \mathrm{~cm}^{-1}\right)$ [37] and thermodynamic stability and corrosion resistance due to the presence of a triple covalent bond between titanium and nitrogen. In this work, titanium nitride (TiN) is investigated as a novel cathode material for 
Li/dissolved polysulfide batteries since it can adsorb lithium polysulfides effectively and transfer electrons in a facile manner. As revealed by X-ray photoelectron spectroscopy (XPS) analysis, sulfur interacts with TiN nanoparticles during the discharge process, and resulted in S-Ti-N, which retains the sulfur species on the cathode surface. The adsorbed higher order polysulfide species undergo reduction to lower order polysulfides by transfer of electrons from the TiN electrode. As a result, the active material and surface area loss were reduced and the capacity and capacity retention of the cell were enhanced.

\section{Experimental Details}

\subsection{Preparation of Titanium Nitride}

Titanium oxide powder $\left(\mathrm{TiO}_{2}, 10-25 \mathrm{~nm}\right.$ size, US Research Nanomaterials) was used as precursor. The powder was first loaded into a zirconia boat and placed in a tubular reactor, which was connected to the gas feed system. Initially, the reactor was purged using 150 $\mathrm{mL} / \mathrm{min}$ Argon (Ar) gas for $1 \mathrm{~h}$; followed by $200 \mathrm{~mL} \mathrm{~min}^{-1}$ pure $\mathrm{NH}_{3}$ gas for 30 min to stabilize the gas flow. The reactor was then heated to $250{ }^{\circ} \mathrm{C}$, in $8 \mathrm{~h}$, held for $40 \mathrm{~min}$, then raised to $1000{ }^{\circ} \mathrm{C}$ over $3 \mathrm{~h}$ and maintained for $1 \mathrm{~h}$. The furnace cooled down to room temperature followed by flowing $150 \mathrm{~mL} \mathrm{~min}^{-1} \mathrm{Ar}$ gas overnight.

\subsection{Fabrication of electrodes and Cell assembly}

The cathode slurry was prepared by adding $10 \mathrm{wt} \%$ of Poly (vinylidene fluoride) PVDF, as binder and N-methyl pyrrolidinone (NMP) as solvent to the cathode materials (TiN). The slurry was then coated on aluminum (Al) foil $\left(0.1 \mathrm{~mm}\right.$ thick) and dried at $80{ }^{\circ} \mathrm{C}$ under vacuum for $12 h$. 
Elemental sulfur $\mathrm{S}_{8}$, lithium sulfide $\mathrm{Li}_{2} \mathrm{~S}$, Bis(trifluoromethane)sulfonimide lithium salt $\mathrm{LiN}\left(\mathrm{SO}_{2} \mathrm{CF}_{3}\right)_{2}$, LiTFSI, triethylene glycol dimethyl ether $\left(\mathrm{TG}_{3}\right)$, were purchased from Aldrich and used as received. Catholyte solutions with $0.2,0.6,0.8 \mathrm{M} \mathrm{Li}_{2} \mathrm{~S}_{8}, 0.1 \mathrm{M} \mathrm{LiTFSI}$, and $1 \mathrm{M}$ $\mathrm{LiNO}_{3}$ were prepared by stirring appropriate amounts of $\mathrm{S}_{8}$ and $\mathrm{Li}_{2} \mathrm{~S}$ into $\mathrm{TG}_{3}$ at $70{ }^{\circ} \mathrm{C}$ for $8 \mathrm{~h}$. $10 \mu \mathrm{L}$ of catholyte solution was added on the positive electrodes with $7 \mathrm{mg} \mathrm{cm}^{-2}$ electrode loading. Coin cells (CR2032) were assembled using polypropylene separator (Celgard 2400) and lithium foil anode inside the Ar-filled glove box.

\subsection{Characterization and Electrochemical measurements}

The phase purity of the cathode electrode materials was characterized using a Rigaku Miniflex 600 X-Ray Diffractometer. Cathode material morphology was characterized with field emission scanning electron microscopy (JEOL 7600F, FESEM). The specific surface areas of the electrode materials were measured by Braunauer-Emmet-Teller (BET) multimolecular adsorption method (Micromeritics Tristar II surface area/porosimeter). Galvanostatic discharge-charge tests were conducted using a Maccor Model 4200 Automated Test System between the voltage range of 1.5 to $3 \mathrm{~V}$ and 1.8 to $3 \mathrm{~V}\left(\mathrm{vs}\right.$. Li/Li $\left.{ }^{+}\right)$at room temperature. Cyclic voltammetry and electrochemical impedance spectroscopy (EIS) measurements were applied using a Gamry potentiostat reference 3000 . The voltammetry was performed at a scan rate of $0.05 \mathrm{mV} \mathrm{s}^{-1}$, and a voltage range of 3 to $1.5 \mathrm{~V}\left(\mathrm{vs}\right.$. Li/ $\left.\mathrm{Li}^{+}\right)$. EIS were recorded between $1 \mathrm{MHz}$ and $0.1 \mathrm{~Hz}$, and $\mathrm{AC}$ amplitude of $10 \mathrm{mV}$ at room temperature.

\section{Results and discussion}

\subsection{Structure and morphology}


Nanostructured TiN was prepared by heating titanium oxide $\left(\mathrm{TiO}_{2}\right)$ under an ammonia atmosphere. Crystal structure of the prepared TiN analyzed by X-ray diffraction (XRD) (Fig. 1a) presents five diffraction peaks of TiN (111), (200), (220), (311) and (222). The positions and intensities of TiN diffraction peaks can be indexed to the face-centered cubic phase structure of TiN (JCPDS file no. 38-1420) with lattice constant $a=0.424 \mathrm{~nm}$ (Fig. 1b). Crystallite size was calculated to be $16 \mathrm{~nm}$ from broadening of the diffraction peak using Scherrer's equation [38].

a)
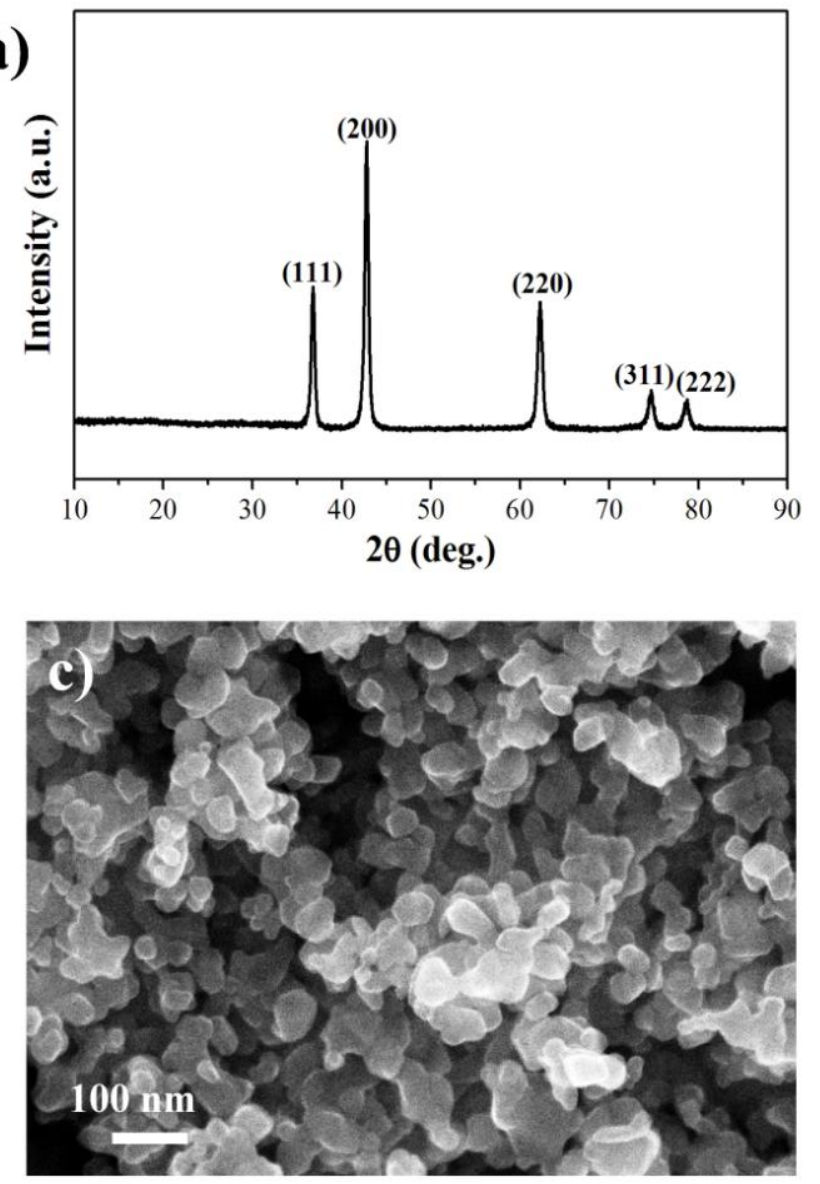

b)
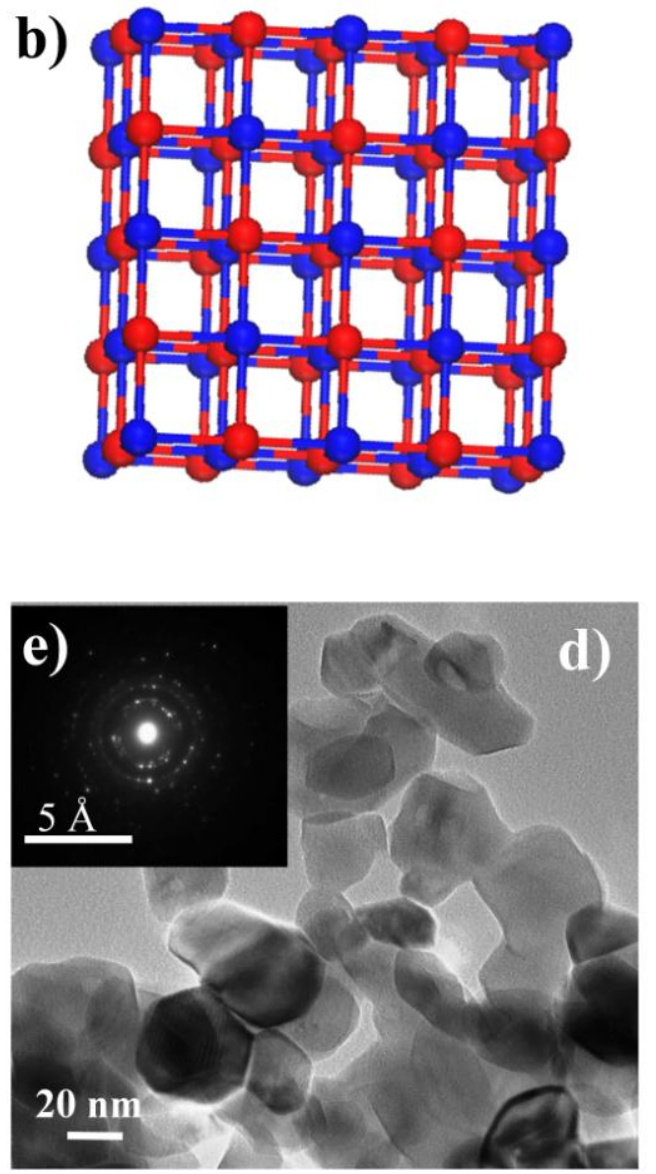

Fig. 1. (a) Powder XRD pattern of TiN, (b) Face-centered cubic structure of TiN (blue and red spheres represent $\mathrm{Ti}$ and $\mathrm{N}$ atoms respectively, (c) SEM image of TiN powder,

(d) TEM image of TiN powder, (e) SAED pattern of TiN. 


\subsection{Electrochemical performance}

The electrochemical performance of the $\mathrm{TiN}$ cathode at a $0.1 \mathrm{C}$ rate was examined with an $\mathrm{Al}$ foil without TiN coating, and TiN coated Al foil with loadings of $\left(3,6\right.$ and $\left.7 \mathrm{mg} \mathrm{cm}^{-1}\right)$ and with a $0.2 \mathrm{M} \mathrm{Li}_{2} \mathrm{~S}_{8}$ catholyte concentration. The results are been presented and discussed in (Fig. $\mathrm{S} 1$ of the Electronic Supplementary Information). In addition, the effect of $\mathrm{Li}_{2} \mathrm{~S}_{8}$ catholyte concentrations on Li-S battery performance with TiN cathode has been investigated. It is observed that the capacity and cycle performance of the Li-S battery can be influenced by the catholyte concentration. The capacity fade of $52 \%, 47 \%$, and $33 \%$ after 100 cycles was calculated for $0.2,0.6$, and $0.8 \mathrm{M} \mathrm{Li}_{2} \mathrm{~S}_{8}$ concentrations, respectively. Although cells with 0.6 and $0.8 \mathrm{M}$ concentrations of $\mathrm{Li}_{2} \mathrm{~S}_{8}$ revealed more stable performance, their capacities stay lower than the cell with $0.2 \mathrm{M} \mathrm{Li}_{2} \mathrm{~S}_{8}$ during 100 cycles. This could be due to the high $\mathrm{Li}_{2} \mathrm{~S}_{8}$ catholyte concentration, which reduces the $\mathrm{Li}$ ion diffusion into the cathode electrode and wettability of the electrode surface by the electrolyte. It was also reported that increasing 
viscosity might lead to higher active material loss as a result of the insoluble lithium polysulfides $\left(\mathrm{Li}_{2} \mathrm{~S}_{2}\right.$, and $\left.\mathrm{Li}_{2} \mathrm{~S}\right)$ formation, which were detected on the surface of cathode electrode [39, 40]. Insoluble lithium polysulfide deposition during cycling can cause capacity fading and lower cyclability, thus, irrespective of different catholyte concentration, similar capacities (around $700 \mathrm{mAh} \mathrm{g}^{-1}$ ) were observed after 100 cycles.
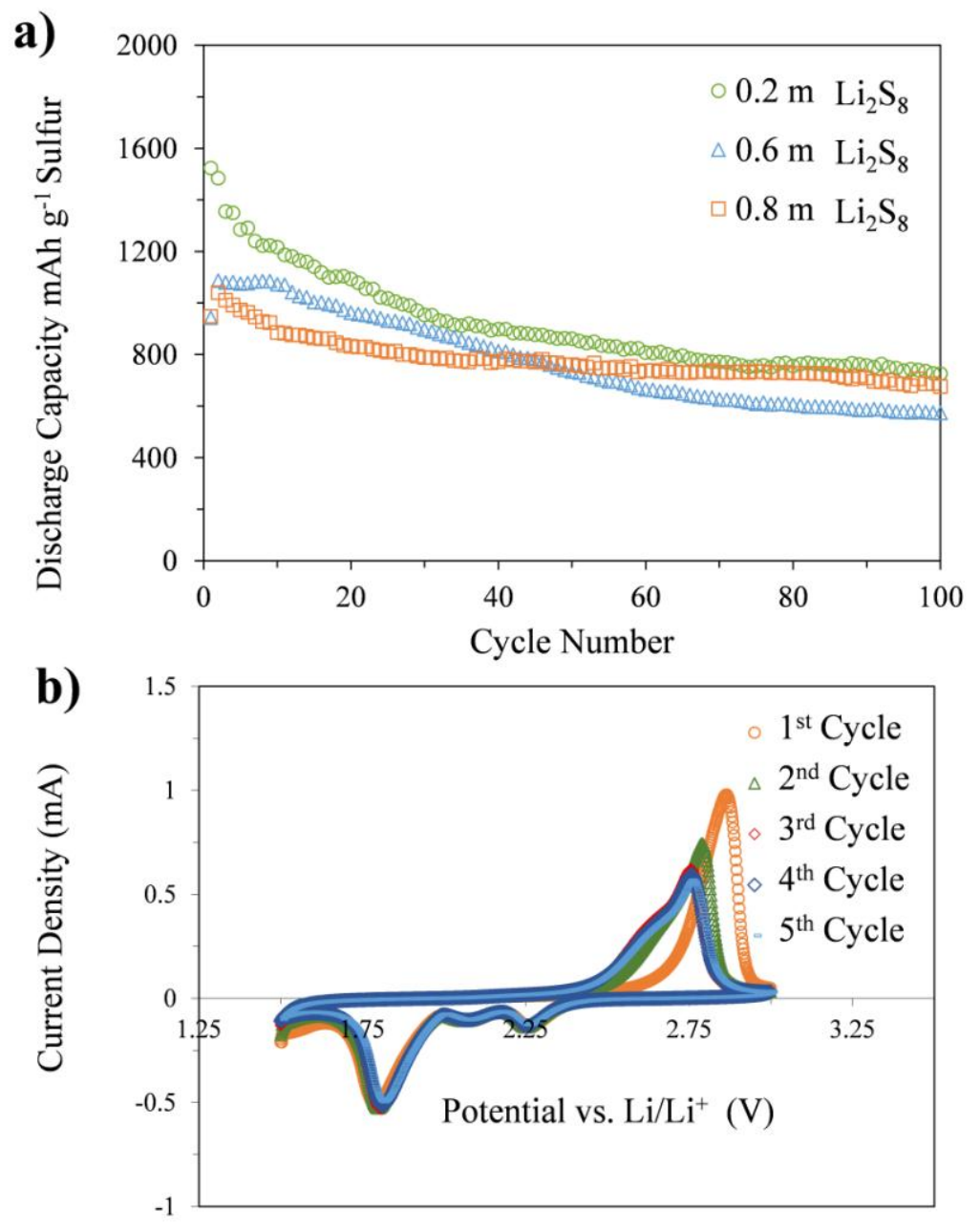

Fig. 2. (a) Cycling performances of the battery with $\mathrm{TiN}$ cathode and different $\mathrm{Li}_{2} \mathrm{~S}_{8}$ catholyte concentrations, (b) Cyclic voltammograms recorded for TiN cathode with $0.2 \mathrm{M} \mathrm{Li}_{2} \mathrm{~S}_{8}$ catholyte concentration, at a scan rate of $0.05 \mathrm{mV} \mathrm{s}^{-1}$. 
In order to have a better understanding of $\mathrm{TiN}$ electrode activity towards the polysulfide conversion reactions, cyclic voltammetry was performed for a cell with a $0.2 \mathrm{M} \mathrm{Li}_{2} \mathrm{~S}_{8}$ catholyte concentration at a scan rate of $0.05 \mathrm{mV} \mathrm{s}^{-1}$ (Fig. 2b). The typical sulfur redox reactions with one oxidation and two reduction peaks were observed for all cycles. In general, reduction of $\mathrm{Li}_{2} \mathrm{~S}_{8}$ to $\mathrm{Li}_{2} \mathrm{~S}$ occurs through a series of intermediate $\mathrm{Li}_{2} \mathrm{~S}_{\mathrm{x}}$ species $(2<\mathrm{X}<8)$ at different potentials [19], The higher voltage cathodic peak corresponds to the reduction of dissolved $\mathrm{Li}_{2} \mathrm{~S}_{8}$ in the catholyte on the surface of the cathode to soluble higher order lithium polysulfide $\mathrm{Li}_{2} \mathrm{~S}_{\mathrm{x}} \quad(4<\mathrm{x}<6)$, and the lower voltage cathodic peak represents the further reduction of polysulfides to insoluble lithium sulfides $\left(\mathrm{Li}_{2} \mathrm{~S}_{2}\right.$ and $\left.\mathrm{Li}_{2} \mathrm{~S}\right)$ [19]. The final region that occurs lower than $1.8 \mathrm{~V}$ potential is associated with the deeper reduction of $\mathrm{Li}_{2} \mathrm{~S}_{2}$ to $\mathrm{Li}_{2} \mathrm{~S}$, both of which are insoluble in most electrolyte media $[3,19,20]$. Therefore, by limiting the lower voltage to $1.8 \mathrm{~V}$, with less $\mathrm{Li}_{2} \mathrm{~S}$ formation, active material and active surface area loss should be suppressed.

\subsubsection{Effect of voltage limit}

Fig. 3a and 3b show the galvanostatic discharge-charge (GDC) profiles of the TiN electrode at $0.1 \mathrm{C}$ rate, with $0.2 \mathrm{M} \mathrm{Li}_{2} \mathrm{~S}_{8}$ catholyte concentration and voltage limits of $1.5-3.0 \mathrm{~V}$ and 1.8$3.0 \mathrm{~V}$, respectively. They both demonstrated two plateaus in the voltage range of 2.45 and $2.0 \mathrm{~V}\left(\mathrm{vs} . \mathrm{Li} / \mathrm{Li}^{+}\right)$. The higher and lower voltage plateaus correspond to the conversion of $\mathrm{Li}_{2} \mathrm{~S}_{8}$ to higher order $\left(\mathrm{Li}_{2} \mathrm{~S}_{n} \mathrm{n}>4\right)$ and lower order lithium polysulfide $\left(\mathrm{Li}_{2} \mathrm{~S}_{n} n<4\right)$, respectively. These two plateaus correspond to $25 \%$ and $75 \%$ of the practical capacity. By limiting the lower

voltage limit to 1.8 , a small percent of capacity was confined. However, the overall capacity was enhanced. Fig. $3 c$ shows the performance of the cell with a narrow voltage limit of 1.8 to 
$3.0 \mathrm{~V}$, which exhibits almost $30 \%$ higher capacity retention compared to the cell with voltage limit of 1.5 to $3.0 \mathrm{~V}$. The capacity of $726 \mathrm{mAh} \mathrm{g}^{-1}$ sulfur after 100 cycles at $0.1 \mathrm{C}$ rate (1.5 to $3.0 \mathrm{~V}$ ) is comparable to reported capacities for lithium/dissolved polysulfide systems with the same voltage limit, such as capacity of $789 \mathrm{mAh} \mathrm{g}^{-1}$ and $600 \mathrm{mAh} \mathrm{g}^{-1}$ after 100 cycles for $\mathrm{Pt} /$ graphene cathode with $0.2 \mathrm{M} \mathrm{Li}_{2} \mathrm{~S}_{8}$ catholyte concentration [24], and vertically-aligned carbon nanotubes with $0.3 \mathrm{M} \mathrm{Li}_{2} \mathrm{~S}_{6}$ concentration [41] respectively. However, with a narrower voltage limit (1.8 to $3.0 \mathrm{~V})$, a higher capacity, $1,040 \mathrm{mAh} \mathrm{g}^{-1}$ sulfur after 100 cycles at $0.1 \mathrm{C}$ rate, was observed.
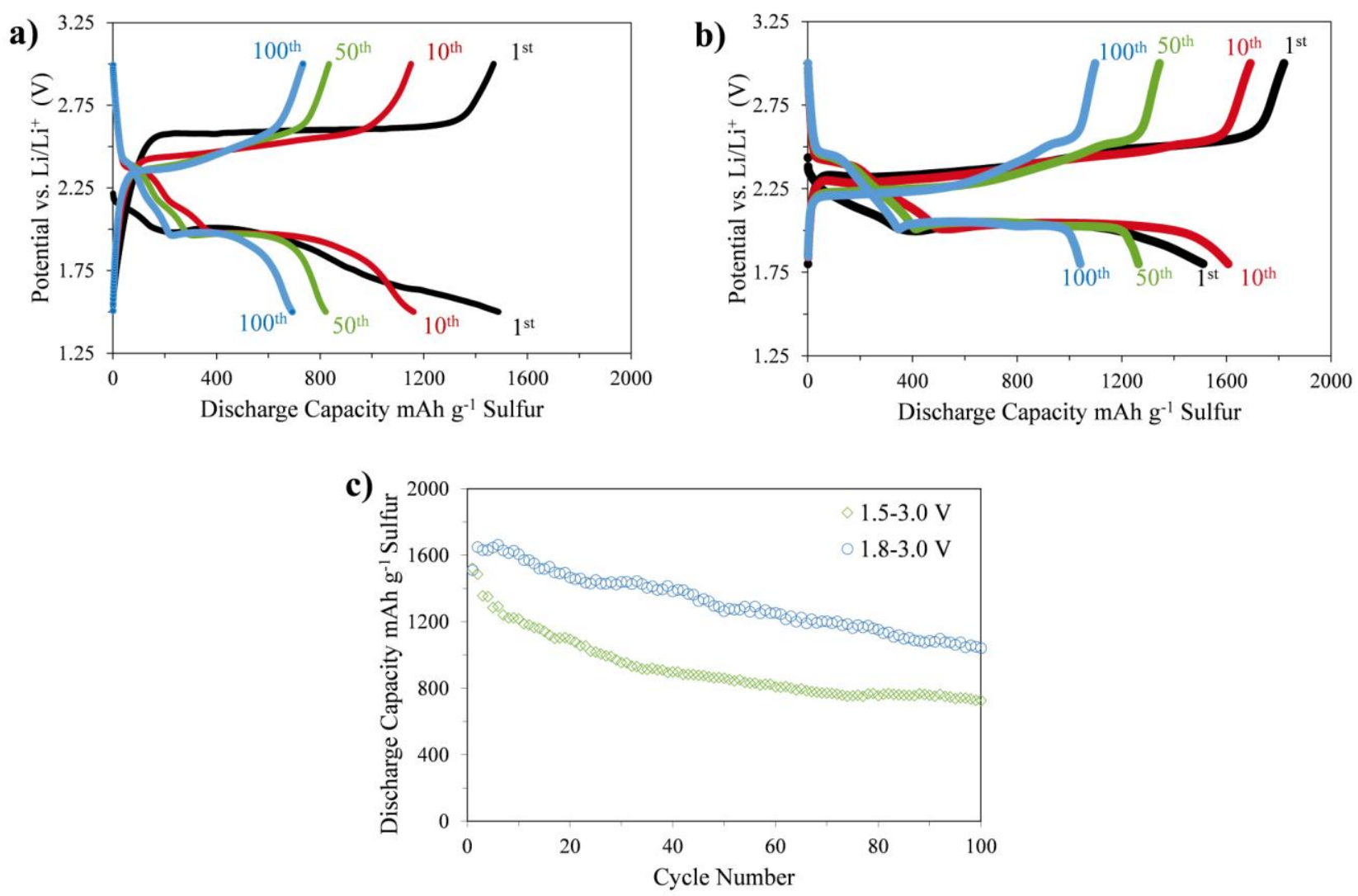

Fig. 3. Effect of voltage limit on the Li/dissolved polysulfide battery performances at $0.1 \mathrm{C}$ rate: (a) GDC profiles in the voltage limit 1.5-3.0 V (b) GDC profiles in the voltage limit 1.8-3.0 V, (c) Cycling performances. 
AC impedance measurements between the $10^{\text {th }}$ and $100^{\text {th }}$ cycles (Fig. S2) also suggest that the charge transfer resistance at the TiN/electrolyte interface increased almost $37 \Omega$ for the voltage limit of $1.5 \mathrm{~V}$; while only a $5 \Omega$ increase was observed for the voltage limit of $1.8 \mathrm{~V}$ (Table. S1). The increase in resistance can be attributed to the passivation layer formation on the TiN electrode surface, which decreases the conductive surface area of the electrode.
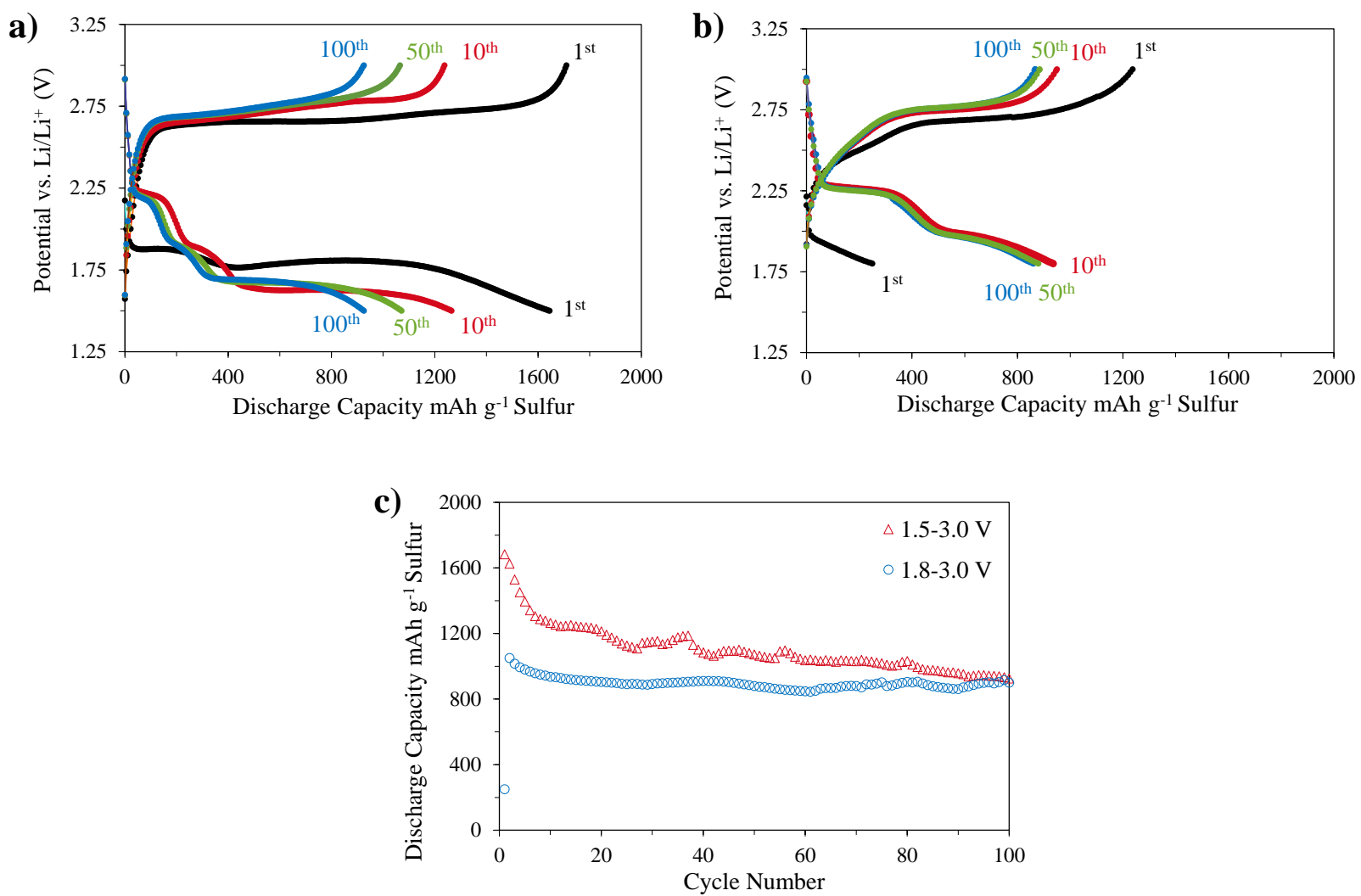

Fig. 4. Effect of voltage limit on the Li/dissolved polysulfide battery performances at $1.0 \mathrm{C}$ rate: (a) GDC profiles in the voltage limit 1.5-3.0 V (b) GDC profiles in the voltage limit 1.8-3.0 V, (c) Cycling performances.

Cycling performance of the cells was also measured at $1.0 \mathrm{C}$ and the results are plotted in Fig. 4. Capacity retention of the cells with $1.5-3.0 \mathrm{~V}$ and 1.8-3.0 $\mathrm{V}$ limits at $1.0 \mathrm{C}$ rate per 100 
cycles were measured to be $55 \%$ and $83 \%$, respectively. GDC profiles at a $1.0 \mathrm{C}$ rate presented in Fig. 4a indicate that insoluble polysulfides $\left(\mathrm{Li}_{2} \mathrm{~S}_{2}\right.$ and $\left.\mathrm{Li}_{2} \mathrm{~S}\right)$ started to form almost at the voltage of 1.5 . In contrast, at $0.1 \mathrm{C}$ rate (Fig. $3 \mathrm{a}$ ), significant amount of insoluble polysulfides were formed. Therefore, restricting the lower voltage limit to $1.8 \mathrm{~V}$ at the $1.0 \mathrm{C}$ rate did not significantly reduce solid polysulfide formation, however, it reduced the overall capacity.

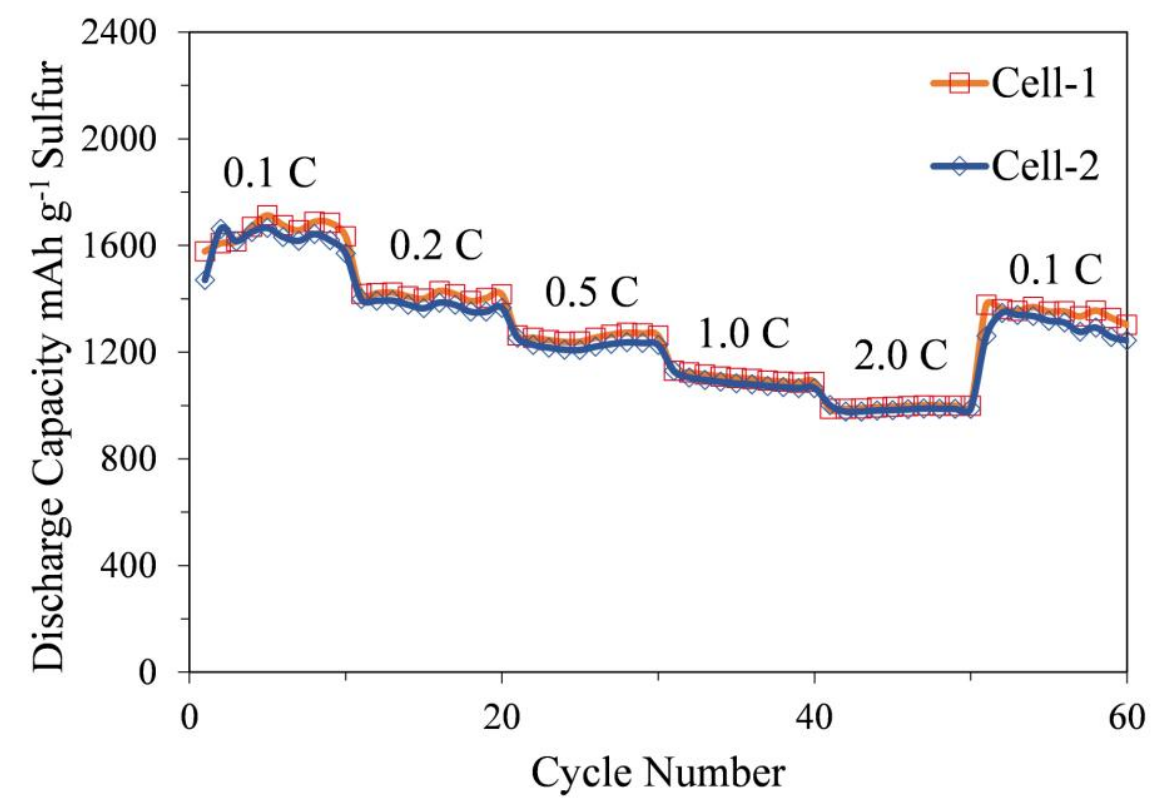

Fig. 5. Rate capability at different current rates in the voltage limit 1.8-3.0 V.

In addition, the rate capability of the TiN electrodes was studied at different $\mathrm{C}$ rates for two cells with the same configuration (Fig. 5). The $C$ rate is based on the theoretical capacity of sulfur ( $\mathrm{C}=1675 \mathrm{mAh} \mathrm{g}^{-1}$ sulfur). The cells were first subjected to a low $0.1 \mathrm{C}$ rate to obtain stable nominal capacity. Subsequent cycling was performed at higher current rates of 0.2 , $0.5,1.0$, and $2.0 \mathrm{C}$ each for 10 cycles. Finally, it was reverted to $0.1 \mathrm{C}$ for 10 additional cycles. Interestingly, cell capacity retention increases as the $C$ rate increases. The results 
show a very low rate of capacity fade $(\sim 1 \%)$ at the $2.0 \mathrm{C}$ rate, compared to 6 percent at the $0.1 \mathrm{C}$ rate. Although the specific capacity decreases with increasing cycle numbers, the cell recovered most of its capacity when the current rate was returned back to $0.1 \mathrm{C}$.

\subsection{Morphological changes of the cathodes}

Microstructural changes of the TiN electrodes during cycling were ascertained by SEM (Fig. 6a-c). After the first discharge process to $1.8 \mathrm{~V}$, some precipitation was detected on the electrode surface, which formed a thin passivation layer on the TiN surface (Fig. 6a and S3a). This precipitation appeared to be reduced after the first charging process to $3.0 \mathrm{~V}$ (Fig. $6 \mathrm{~b}$ and S3b). However, after the $100^{\text {th }}$ charge, besides having more passivation layer formed on the electrode surface, the grains size seems to be larger, which could be due to particle agglomeration or coverage of particles with precipitated $\mathrm{Li}_{2} \mathrm{~S}_{2}, \mathrm{Li}_{2} \mathrm{~S}$ and $\mathrm{S}_{8}$ (Fig. 6c).

In order to identify the surface chemical environment of the TiN composites after cycling, X-ray photoelectron spectroscopy (XPS) analysis was conducted on TiN electrodes extracted from cells at the end of the first charged and discharged states. The deconvoluted spectra in the S2p region are presented in Fig. $6 \mathrm{~d}-\mathrm{e}$. When the cell was discharged to $1.8 \mathrm{~V}$, peak binding energies of 160 and $161.2 \mathrm{eV}$ suggested $\mathrm{Li}_{2} \mathrm{~S}$ and $\mathrm{Li}_{2} \mathrm{~S}_{2}$ were formed, respectively [42-44].

The intensity of the $\mathrm{Li}_{2} \mathrm{~S}_{2}$ peak is stronger because the voltage limit of $1.8 \mathrm{~V}$ prevents further $\mathrm{Li}_{2} \mathrm{~S}$ formation. After the first charge, no $\mathrm{Li}_{2} \mathrm{~S}$ peak was observed, which indicates that $\mathrm{Li}_{2} \mathrm{~S}$ was completely oxidized back to higher order lithium polysulfides. However, there is still some $\mathrm{Li}_{2} \mathrm{~S}_{2}$ precipitation detected on the TiN cathode surface. Moreover, long chain polysulfides $\mathrm{Li}_{2} \mathrm{~S}_{\mathrm{n}}(\mathrm{n} \geq 4)$ were detected at $162.6 \pm 0.1 \mathrm{eV}$ [42-44] for both first discharge and charge status, consistent with incomplete redox reactions before the formation of solid electrolyte interlayer 

prevents the continuous electron transfer from the $\mathrm{Li}$ anode to dissolved polysulfides and suppresses redox shuttle reactions [45].
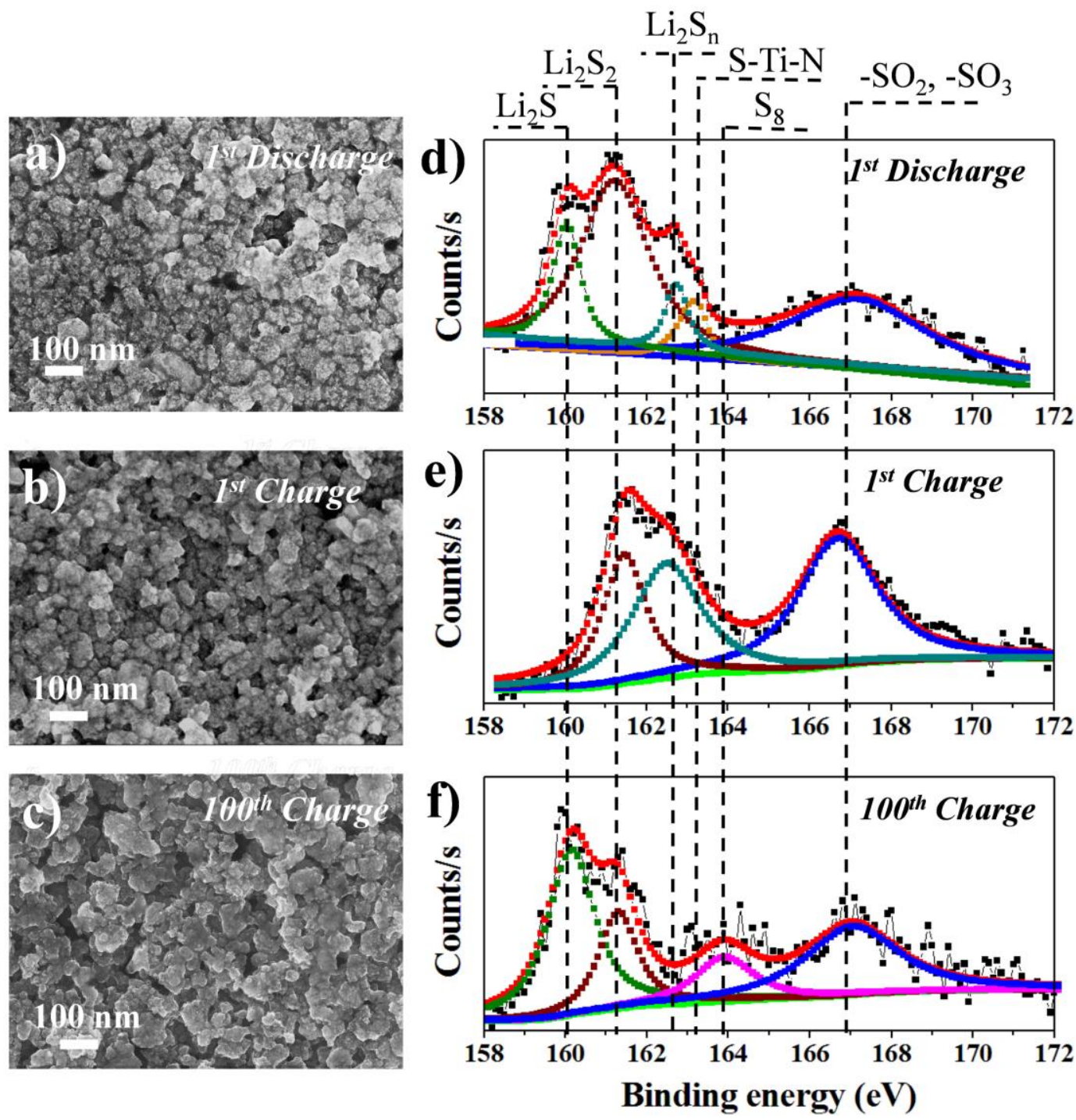

Fig. 6. Post-mortem analysis of the TiN electrodes; (a,d) First discharge, (b,e) First cycle in charged state, $(c, f) 100^{\text {th }}$ cycle in charged state. First and second columns are corresponded to the SEM images and deconvoluted XP S2p spectra of the TiN electrodes. Original and fitted XPS data are represented with black and red lines respectively. 
A strong peak of $\mathrm{Li}_{2} \mathrm{~S}$ in addition to $\mathrm{Li}_{2} \mathrm{~S}_{2}$ peak was detected on the XPS spectra of the electrode after the $100^{\text {th }}$ charge, which explains the capacity fading of the Li-S cell after 100 cycles. The peaks with the binding energy of $167 \pm 0.2 \mathrm{eV}$, which can be attributed to the $-\mathrm{S}-\mathrm{O}$ bonding in $-\mathrm{SO}_{3}$ and $-\mathrm{SO}_{2}$ species, can be found in all samples. These species are originated from the electrolyte $[43,46]$. In addition to the long chain polysulfides detected in the S2p spectrum of the first discharge state, an additional sulfur peak was observed at $163.1 \mathrm{eV}$. This peak, which is sited within the range of Ti-S binding energy, can be attributed to the S-Ti-N bond. To confirm the $\mathrm{TiN}-\mathrm{Li}_{2} \mathrm{~S}_{8}$ interaction, $100 \mathrm{mg}$ of TiN was mixed with $5 \mathrm{ml}$ of $0.01 \mathrm{M}$ catholyte solution and stirred (Fig. S4). The catholyte color changed from bright yellow-green to colorless within $30 \mathrm{~min}$, which indicates that the polysulfides were adsorbed by TiN powder. The adsorbed higher order polysulfides were reduced by transfer of electrons from the TiN electrode and converted to the lower order polysulfides $\left(\mathrm{Li}_{2} \mathrm{~S}_{2}\right.$ and $\left.\mathrm{Li}_{2} \mathrm{~S}\right)$. In addition, as a result of reversible S-Ti-N binding interactions, the active material loss due to lower order polysulfides precipitation decreases.

\section{Conclusions}

In summary, we have shown that TiN is a promising cathode material for advanced Li/dissolved polysulfide batteries. We demonstrate that changing the lower voltage limit from $1.5 \mathrm{~V}$ to $1.8 \mathrm{~V}$ at $0.1 \mathrm{C}$ rate highly enhances the cycling performance of the Li-S battery due to decreasing the insoluble polysulfides formation on the cathode electrode. Furthermore, the existence of S-Ti-N bonding at the electrode surface observed by XPS analysis is indicative of strong interactions between polysulfides and TiN. This could effectively mitigate the insoluble lithium sulfide formation on the cathode surface, which minimizes the active 
material and surface area loss and improves the capacity retention. The resultant cells deliver high capacity of almost $1,040 \mathrm{mAh} \mathrm{g}^{-1}$ sulfur after 100 cycles at $0.1 \mathrm{C}$ rate.

\section{Acknowledgment}

Financial support from the Department of Energy (Grant DEEE0002106) is gratefully acknowledged.

[1] Duck-Rye Chang, Suck-Hyun Lee, Sun-Wook Kim, Hee-Tak Kim, J. Power Sources, 112 (2002) 452-460.

[2] S.-H. Chung, A. Manthiram, Electrochim. Acta, 107 (2013) 569-576.

[3] ARUMUGAM MANTHIRAM, YONGZHU FU, Y.-S. SU, Acc. Chem. Res., 46 (2013) 11251134.

[4] J. Wang, S.Y. Chew, Z.W. Zhao, S. Ashraf, D. Wexler, J. Chen, S.H. Ng, S.L. Chou, H.K. Liu, Carbon, 46 (2008) 229-235.

[5] L. Yuan, H. Yuan, X. Qiu, L. Chen, W. Zhu, J. Power Sources, 189 (2009) 1141-1146.

[6] Y. Fu, A. Manthiram, J. Phys. Chem. C, 116 (2012) 8910-8915.

[7] C. Liang, N.J. Dudney, J.Y. Howe, Chem. Mater., 21 (2009) 4724-4730.

[8] N. Li, M. Zheng, H. Lu, Z. Hu, C. Shen, X. Chang, G. Ji, J. Cao, Y. Shi, Chem. Commun, 48 (2012) 4106-4108.

[9] S.-H. Chung, A. Manthiram, Chem. Commun, 50 (2014) 4184-4187.

[10] M.K. Song, Y. Zhang, E.J. Cairns, Nano Lett, 13 (2013) 5891-5899.

[11] D.V. Esposito, K.D. Dobson, B.E. McCandless, R.W. Birkmire, J.G. Chen, J. Electrochem. Soc., 156 (2009) B962-B969.

[12] Z.W. Seh, J.H. Yu, W. Li, P.-C. Hsu, H. Wang, Y. Sun, H. Yao, Q. Zhang, Y. Cui, Nat Commun, 5 (2014).

[13] X. Ji, S. Evers, R. Black, L.F. Nazar, Nat Commun, 2 (2011) 325.

[14] S. Evers, T. Yim, L.F. Nazar, J. Phys. Chem. C, 116 (2012) 19653-19658.

[15] J.R. SMITH, F.C. WALSH, J Appl Electrochem, 28 (1998) 1021-1033.

[16] C.J. Hart, M. Cuisinier, X. Liang, D. Kundu, A. Garsuch, L.F. Nazar, Chem. Commun, 51 (2015) 2308-2311.

[17] Q. Pang, D. Kundu, M. Cuisinier, L.F. Nazar, Nat Commun, 5 (2014) 4759.

[18] S.S. Zhang, J.A. Read, J. Power Sources, 200 (2012) 77-82.

[19] S.S. Zhang, J. Power Sources, 231 (2013) 153-162.

[20] N. Mosavati, V.R. Chitturi, L.M.R. Arava, S.O. Salley, K.Y.S. Ng, Electrochim. Acta, 185 (2015) 297-303.

[21] C. Barchasz, F. Mesguich, J. Dijon, J.-C. Leprêtre, S. Patoux, F. Alloin, J. Power Sources, 211 (2012) 19-26. 
[22] R. Demir-Cakan, M. Morcrette, Gangulibabu, A. Guéguen, R. Dedryvère, J.-M. Tarascon, Energy Environ Sci, 6 (2013) 176.

[23] G. Babu, K. Ababtain, K.Y. Ng, L.M. Arava, Sci Rep, 5 (2015) 8763.

[24] H. Al Salem, G. Babu, C. V. Rao, L.M.R. Arava, J. Am. Chem. Soc, 137 (2015) $11542-$ 11545.

[25] H. Zheng, S. Fang, Z. Tong, G. Pang, L. Shen, H. Li, L. Yang, X. Zhang, J. Mater. Chem. A., 3 (2015) 12476-12481.

[26] M.-S. Balogun, M. Yu, C. Li, T. Zhai, Y. Liu, X. Lu, Y. Tong, J. Mater. Chem. A., 2 (2014) 10825.

[27] B. Das, M.V. Reddy, G.V.S. Rao, B.V.R. Chowdari, J. Mater. Chem., 22 (2012) 17505.

[28] M.-S. Balogun, W. Qiu, W. Wang, P. Fang, X. Lu, Y. Tong, J. Mater. Chem. A, 3 (2015) 1364-1387.

[29] K.H.T. Raman, T.R. Penki, N. Munichandraiah, G.M. Rao, Electrochim. Acta, 125 (2014) 282-287.

[30] S. Dong, X. Chen, X. Zhang, G. Cui, Coordination Chemistry Reviews, 257 (2013) 19461956.

[31] X. Lu, G. Wang, T. Zhai, M. Yu, S. Xie, Y. Ling, C. Liang, Y. Tong, Y. Li, Nano Lett, 12 (2012) 5376-5381.

[32] Q. Sun, Z.-W. Fu, Electrochim. Acta, 54 (2008) 403-409.

[33] D.K. Nandi, U.K. Sen, D. Choudhury, S. Mitra, S.K. Sarkar, ACS Appl Mater Interfaces, 6 (2014) 6606-6615.

[34] H.-C. Park, K.-H. Lee, Y.-W. Lee, S.-J. Kim, D.-M. Kim, M.-C. Kim, K.-W. Park, J. Power Sources, 269 (2014) 534-541.

[35] N. Pereira, L.C. Klein, G.G. Amatucci, J. Electrochem. Soc., 149 (2002) A262.

[36] F. Gillot, J. Oró-Solé, M.R. Palacín, J. Mater. Chem., 21 (2011) 9997.

[37] D. Choi, P.N. Kumta, J. Am. Ceram. Soc, 94 (2011) 2371-2378.

[38] A.R. West, Wiley, (1996).

[39] J.-W. Choi, J.-K. Kim, G. Cheruvally, J.-H. Ahn, H.-J. Ahn, K.-W. Kim, Electrochim. Acta, 52 (2007) 2075-2082.

[40] W. Wang, Y. Wang, Y. Huang, C. Huang, Z. Yu, H. Zhang, A. Wang, K. Yuan, J Appl Electrochem, 40 (2009) 321-325.

[41] S. Liatard, K. Benhamouda, A. Fournier, J. Dijon, C. Barchasz, Electrochim. Acta, 187 (2016) 670-676.

[42] Y.S. Su, Y. Fu, T. Cochell, A. Manthiram, Nat Commun, 4 (2013) 2985.

[43] Z. Jin, K. Xie, X. Hong, Z. Hu, J. Power Sources, 242 (2013) 478-485.

[44] X. Liang, A. Garsuch, L.F. Nazar, Angew Chem Int Ed Engl, 54 (2015) 3907-3911.

[45] J. Zheng, M. Gu, H. Chen, P. Meduri, M.H. Engelhard, J.-G. Zhang, J. Liu, J. Xiao, J. Mater. Chem. A, 1 (2013) 8464-8470.

[46] X. Liang, C. Hart, Q. Pang, A. Garsuch, T. Weiss, L.F. Nazar, Nat. Commun., 6 (2015). 